\title{
Avaliação de Prescrição de Suplementos de Flúor Pré-Natal em Curitiba e Região Metropolitana
}

\author{
Evaluation of Prenatal Fluoride Supplement Prescription \\ in Curitiba and Metropolitan Region \\ Estela M. Losso, Georgiana M. Ramalho
}

\begin{abstract}
RESUMO
Objetivo: avaliar a prescrição de suplementos de flúor durante o pré-natal por ginecologistas e obstetras na cidade de Curitiba e região metropolitana.

Métodos: foram enviados questionários a 223 médicos especialistas em ginecologia e obstetricia. As perguntas abordavam a prescrição ou não de flúor a gestantes, tempo de formado e local de trabalho, entre outros parâmetros. Para análise estatística empregou-se o teste t de Student, análise de variância (ANOVA), teste do $\chi^{2}$ ou teste exato de Fisher.

Resultados: foram devolvidos 137 questionários, correspondendo a 30\% (137/441) dos profissionais da área de atuação e a 61,4\% (137/223) dos questionários enviados. O flúor pré-natal é prescrito por $47,5 \%$ dos profissionais, dos quais $60 \%$ prescrevem porque acreditam em uma formação dentária melhor e na prevenção de cárie dos filhos. Os profissionais que não prescrevem possuem menor tempo de formado $(t=2,27 ; p<0,05)$, sendo que os que trabalham exclusivamente no serviço público prescrevem menos do que os do setor privado (teste de Fisher, $p<0,05$ ).

Conclusão: é grande o número de profissionais ginecologistas-obstetras que prescrevem flúor no pré-natal, apesar de os estudos recentes não indicarem qualquer vantagem para a criança. Portanto, existe a necessidade de uma maior divulgação da abordagem do mecanismo de ação, indicação e uso clínico do flúor para estes profissionais.
\end{abstract}

PALAVRAS-CHAVE: Gravidez normal. Flúor. Pré-natal. Suplementação alimentar. Saúde bucal.

\section{Introdução}

Antigamente acreditava-se que o flúor administrado sistemicamente tivesse uma ação anticariogênica devido a sua incorporação ao esmalte durante o processo de mineralização, formando a fluorapatita, ao invés de hidroxiapatita, deste modo tornando o esmalte dentário mais resistente ao processo de desmineralização ${ }^{1}$.

Embora o flúor continue sendo utilizado no controle e prevenção da cárie dentária, atualmente sua ação é atribuída ao seu efeito local no período pós-eruptivo dos dentes, sendo que a sua presen-

Associação Brasileira de Odontologia - Curitiba - Curso de Especialização em Odontopediatria da UFPR.

Correspondência

Estela Maris Losso

R. Des. Otávio do Amaral, 593/1004

80730-400 - Curitiba - PR

Fax/Fone: (41) 336-5962

e-mail: andreat@bio.ufpr.br ça local favorece a remineralização no processo de desmineralização/remineralização do esmalte. Possui também ação antibacteriana ${ }^{2-4}$. Nesta linha, o flúor sistêmico teria um efeito local ao passar pela cavidade bucal antes de sua ingestão e, após ser absorvido pelo trato gastrointestinal, ao ser secretado na saliva ${ }^{5}$.

O uso sistêmico do flúor na água de abastecimento público é o método mais usado na saúde pública, principalmente em lugares onde a assistência à saúde bucal é deficiente ${ }^{6}$. Este benefício é decorrente da exposição freqüente e de baixa concentração do flúor produzindo seu efeito cariostático $^{7}$. Na ausência do flúor na água de abastecimento, pode- se recomendar a suplementação de flúor na forma de medicamentos ${ }^{8}$.

A postura em relação à suplementação de flúor durante o pré-natal tem se modificado ao longo do tempo. Inicialmente alguns pesquisadores defendiam o seu uso ${ }^{9-13}$ para a prevenção da cárie 
dentária, relatando uma melhoria na anatomia da superficie oclusal dos molares decíduos e dos primeiros molares permanentes e uma redução de até $99 \%$ no diagnóstico de cáries dentárias nas crianças no grupo em que a mãe fez suplementação de flúor na gravide $z^{10}$.

Entretanto, a efetividade da suplementação do flúor durante o pré-natal foi questionada ${ }^{14}$ e até mesmo considerada como não recomendada ${ }^{15}$, principalmente quando se leva em consideração que, no desenvolvimento da dentição das crianças, as áreas suscetiveis à cárie dentária se calcificam somente após o nascimento.

Deutsch e Gedalia ${ }^{16}$, após estudarem a concentração de flúor no esmalte de fetos humanos, afirmaram que a suplementação de flúor na gestação teria pouco ou nenhum efeito na prevenção de cáries do bebê. Leverett et al. ${ }^{17}$ acompanharam 798 crianças até os 5 anos de idade para verificar se ocorria uma redução da incidência de cárie no grupo com suplementação de flúor pós-natal e outro com suplementação pré e pós-natal, avaliando também a prevalência da fluorose. Os resultados mostraram que $91 \%$ das crianças que receberam a suplementação pós-natal de flúor estavam livres de cárie e que $92 \%$ das crianças que foram submetidas a suplementação pré e pós-natal de flúor não desenvolveram cáries. Observaram também a ocorrência de fluorose em 26 crianças, mas não houve relação com o tipo de suplementação.

Portanto, atualmente a maioria dos autores não recomenda a suplementação de flúor na gestação, pois não há evidências de que ocorra qualquer beneficio aos dentes do feto quando se consideram apenas os estudos metodologicamente adequados ${ }^{3,4,18-20}$.

A suplementação de flúor não é recomendada, como se preconizava antigamente, antes da erupção dos dentes ${ }^{5,21}$. Além disso, o seu uso não é recomendável nas cidades e comunidades em que a água é fluoretada ${ }^{22,23}$.

Apesar destes dados não indicando a suplementação de flúor no período pré-natal, em uma avaliação desta conduta entre ginecologistas-obstetras da cidade de Manaus (AM), foi observado que mais de $80 \%$ dos profissionais indicavam a suplementação de flúor, na forma de composto vitamínico-mineral, durante o período prénatal ${ }^{21}$. Tendo em vista que este é o único trabalho sobre este assunto no Brasil, não sabemos, portanto, se estes dados refletem apenas a situação local ou um fenômeno mais generalizado.

Diante do exposto, o presente trabalho tem como objetivo avaliar o uso da suplementação de flúor pré-natal por ginecologistas-obstetras da cidade de Curitiba e região metropolitana.

\section{Métodos}

Um questionário contendo perguntas sobre a prescrição de suplementos de flúor pré-natal foi preparado e entregue a 223 médicos ginecologistas-obstetras da cidade de Curitiba e região metropolitana no período de maio a julho de 1999. Duzentos e doze profissionais foram selecionados aleatoriamente de uma lista de 441 profissionais, que compreendia os ginecologistas-obstetras credenciados em seguro saúde e registrados no Conselho Regional de Medicina do Paraná e 11 médicos ginecologistas-obstetras plantonistas de um hospital-escola da cidade de Curitiba.

Este questionário abordava questões relativas ao profissional (tempo de exercício profissional e local de trabalho) e questões relativas à prática relacionada à suplementação de flúor no prénatal (prescrição de suplementos de flúor pré-natal, o nome do medicamento utilizado, sua fórmula farmacêutica, o período da gestação em que ocorre a prescrição e justificativa para prescrição ou não destes medicamentos).

Em anexo ao questionário foi entregue uma carta explicando os objetivos do questionário, o caráter voluntário da participação e garantindo o anonimato dos participantes.

Nas comparações entre os grupos em relação ao tempo de formado empregou-se o teste $t$ de Student para medidas independentes. Na comparação entre o tempo de formado de acordo com o local de trabalho dos profissionais que prescrevem foi utilizada a análise de variância (ANOVA) de 1 via. Na avaliação da prescrição ou não de acordo com o local de trabalho empregou-se o teste do $\chi^{2}$, quando possivel, ou o teste exato de Fisher. Considerou-se diferença estatisticamente significante quando $\mathrm{p}<0,05$.

\section{Resultados}

Dos 223 questionários enviados, 137 (61,4\%) foram devolvidos e devidamente preenchidos e 86 $(38,5 \%)$ não foram devolvidos. Considerando-se a amostra total (Tabela 1), observou-se uma diferença estatisticamente significante quanto ao tempo de formado entre os que prescrevem ou não flúor $(t=2,27, p<0,03)$, sendo que os que prescrevem apresentam um maior tempo de formado.

Dividindo-se a amostra de acordo com o local de trabalho (Tabela 1), encontrou-se uma tendência dos profissionais que trabalhavam tanto na clínica privada como no serviço público e que prescreviam flúor de estarem formados há mais tem- 
po do que aqueles que não prescreviam $(t=1,875$, $\mathrm{p}=0,07)$. Não se observou diferença estatisticamente significante no tempo de formado entre os que prescreviam e os que não prescreviam, nos profissionais que trabalhavam apenas na clínica privada $(t=0,97, p>0,10)$. Entre os profissionais que trabalhavam só no serviço público nenhum prescrevia flúor. Este resultado independe do tempo de formado, pois não foram encontradas diferenças estatisticamente significantes entre o tempo de formado dos profissionais que não prescrevem em função do local de trabalho $\left(\mathrm{F}_{1,63}=0,281 ; \mathrm{p}>0,10\right)$.

Tabela 1 - Tempo de formado (em anos) dos profissionais que prescrevem ou não flúor, de acordo com o local de trabalho. Dados representam média \pm DP (número de sujeitos).

\begin{tabular}{lcc}
\hline & $\begin{array}{c}\text { Prescreve } \\
\text { (n) }\end{array}$ & $\begin{array}{c}\text { Não Prescreve } \\
\text { (n) }\end{array}$ \\
\hline Amostra total & $18,4 \pm 7,7$ & $15,7 \pm 6,1^{*}$ \\
Privado & $(65)$ & $(72)$ \\
Público & $18,0 \pm 7,6$ & $16,4 \pm 6,3$ \\
& $(40)$ & $(35)$ \\
Privado + Público & -- & $11,0 \pm 6,9$ \\
& $(0)$ & $(5)$ \\
\hline${ }^{*}$ p $<0,05$ em relação ao grupo Prescreve, teste $t$ de Student & $\left.15,6 \pm 5,6{ }^{*}\right)$
\end{tabular}

* $p<0,05$ em relação ao grupo Prescreve, teste $t$ de Student
(*) $p<0,07$ em relação ao grupo Prescreve, teste $t$ de Student

Os profissionais que trabalham apenas no setor privado e os que trabalham nos setores público e privado (Tabela 1) apresentaram uma tendência maior a prescrever o flúor do que os que trabalham apenas no serviço público (teste exato de Fisher, $\mathrm{p}<0,06$ e $\mathrm{p}<0,08$, respectivamente). Aqueles que trabalham apenas no setor privado não diferiram dos que trabalham nos dois setores $\left(\chi^{2}=1,16 ; p>0,10\right)$. Não se observou diferença em relação ao mês no qual o flúor é prescrito em função do local de trabalho (privado: $3,7 \pm 0,7$; privado + público: $3,7 \pm 1,1$ ), lembrando que os que trabalham exclusivamente no serviço público não prescrevem flúor. Independente do local de trabalho, os que prescrevem flúor fazem-no principalmente no $3^{\circ}$ mês de gravidez $(50,6 \%)$, seguido do $4^{\circ}$ mês $(35,8 \%)$ e 5 o mês $(12,2 \%)$.

A Tabela 2 mostra as justificativas para a prescrição ou não do flúor, sendo a justificativa mais citada para a prescrição uma melhor formação dos dentes do bebê (60\%) e para a não-prescrição o fato de que a água de abastecimento de Curitiba é fluoretada (70\%). Cabe ressaltar que 11\% responderam de acordo com a literatura, ou seja, de que não existem dados científicos atuais indicando que a suplementação de flúor traga qual- quer beneficio para a formação dos dentes da criança.

Tabela 2 - Distribuição dos ginecologistas-obstetras segundo as justificativas apresentadas para a prescrição ou não prescrição de suplementos de flúor pré-natal.

\begin{tabular}{|c|c|}
\hline Justificativa para prescrição $(n=65)$ & $\mathrm{n}(\%)$ \\
\hline $\begin{array}{l}\text { Melhor formação dentária e prevenção de cárie no } \\
\text { bebê }\end{array}$ & $39(60,1)$ \\
\hline Prevenção de cárie dentária na mãe e no bebê & $16(24,5)$ \\
\hline $\begin{array}{l}\text { Associado a complexos vitamínicos, supre a carência } \\
\text { vitamínica da mãe }\end{array}$ & $7(10,8)$ \\
\hline $\begin{array}{l}\text { Prevenção de problemas periodontais na mãe } \\
\text { (sangramento gengival) }\end{array}$ & $2(3,1)$ \\
\hline Prevenção da osteosporose da mãe & $1(1,5)$ \\
\hline \multicolumn{2}{|l|}{ Justificativa para não-prescrição $(n=72)$} \\
\hline Água de abastecimento já é fluoretada & $51(70,8)$ \\
\hline $\begin{array}{l}\text { Já ocorre a prescrição de complexos vitamínicos sem } \\
\text { a necessidade de flúor nos mesmos }\end{array}$ & $10(13,9)$ \\
\hline $\begin{array}{l}\text { Não há provas científicas de que o flúor é benéfico na } \\
\text { gravidez }\end{array}$ & $8(11,2)$ \\
\hline Falta de condição financeira da gestante & $3(4,1)$ \\
\hline
\end{tabular}

\section{Discussão}

Os resultados do trabalho mostram que é grande o número de médicos ginecologistas-obstetras que prescrevem suplementação de flúor, apesar de este procedimento não ser mais recomendado. Portanto, os dados do presente estudo indicam que os resultados de Hanan ${ }^{21}$ não são restritos àquela região do país, embora a freqüência de prescrição de flúor tenha sido menor em Curitiba em relação a Manaus (47\% vs $86 \%$ ). Entretanto, temos que levar em consideração que a água de abastecimento da cidade de Manaus não é fluoretada, ao passo que a do município de Curitiba é, desde 1982. Este fato pode ter contribuído para a taxa menor observada em Curitiba, uma vez que $70 \%$ dos profissionais de Curitiba que não prescrevem flúor citaram este fato para justificar sua conduta. Mais ainda, em Manaus, a suplementação de flúor durante o período pré-natal pode trazer benefícios para a saúde bucal das mães. Em Curitiba apenas 11\% justificaram corretamente a não-prescrição pelo fato de não haver provas científicas de que o flúor seja benéfico para a criança.

O efeito do flúor durante a gravidez para a prevenção de cáries nos dentes do futuro bebê é praticamente nula, já que as áreas susceptíveis se calcificam após o nascimento ${ }^{15,24}$; a suplementação de flúor pré-natal não deve ser recomenda- 
da porque é no período de maturação pré-eruptiva que há maior absorção de minerais e do flúor pelo esmalte dentário, sendo que este período ocorre após o nascimento, exceto para os incisivos anteriores. Além disto, os estudos clínicos iniciais que preconizaram estes beneficios não tinham controles adequados e seus métodos experimentais não eram confiáveis. Logo, não havendo evidência científica que suporte um efeito benéfico para o bebê, o flúor pré-natal não deve ser prescrito às gestantes. Nesta linha, a Academia Americana de Odontopediatria ${ }^{23}$ não recomenda a suplementação de flúor na gestação. No Brasil não existem normas em relação ao assunto.

A prescrição do flúor pré-natal foi maior no grupo com mais tempo de formado, o que pode estar relacionado com informações recebidas há muito tempo, sendo que o conhecimento sobre o mecanismo de ação do flúor mudou nestes 15 anos. Por outro lado, embora o resultado tenha sido estatisticamente significante $(\mathrm{p}<0,05 \%)$, a diferença entre as médias foi de apenas 3 anos, o que do ponto de vista prático pode não ser de grande relevância.

Quanto à prescrição ou não de flúor pré-natal de acordo com o local de trabalho, observamos que entre os profissionais que indicam a prescrição, a maioria trabalha apenas em consultório particular, um número menor exerce a profissão em consultório particular e serviço público e que nenhum profissional que atua exclusivamente em serviço público realiza a prescrição. Este fato pode estar relacionado a um maior contato existente entre médicos e dentistas que trabalham na rede pública, hipótese que deve ser testada em futuros estudos.

O início da prescrição apresenta resultados equilibrados, uma vez que independente do local de trabalho, a maioria dos profissionais prescrevem o flúor a partir do 3o mês de gravidez.

O medicamento mais prescrito $(72,3 \%)$ contém $1 \mathrm{mg}$ de flúor na sua composição, o qual é um composto vitamínico-mineral fluoretado. Cabe ressaltar que o fabricante não recomenda o uso do produto onde a água potável contenha flúor acima de 0,7 ppm. Isto acarreta um problema adicional, pois os suplementos que contém flúor sob a forma de fluoreto de sódio e que também tenham cálcio na composição formam compostos de baixa solubilidade, diminuindo a absorção tanto do flúor como do cálcio ${ }^{25}$. Mais ainda, Hanan ${ }^{21}$ observou que os compostos vitamínicos fluoretados comercializados no Brasil apresentam baixos teores de flúor em comparação com o esperado, havendo evidências de que estes valores tenham sido alterados pela presença de vitaminas e sais minerais.

Considerando os resultados obtidos no pre- sente estudo, é possivel concluir que é expressivo o número de ginecologistas-obstetras que prescrevem o suplemento de flúor pré-natal em Curitiba e na região metropolitana e que são necessárias normas quanto ao uso do suplemento de flúor durante o pré-natal no Brasil.

\section{SUMMARY}

Purpose: to evaluate the prescription of prenatal fluoride supplements by gynecologists and obstetricians in Curitiba and metropolitan region.

Methods: two hundred and twenty-three (223) questionnaires were distributed to gynecologistobstetricians. Questions were about the use of fluoride during pregnancy, time since graduation, workplace, among other parameters. Statistical analyses were carried out using Student's t-test, variance analysis (ANOVA), $\chi^{2}$ test or Fisher exact test.

Results: only 137 questionnaires were returned, which corresponds to $30 \%$ (137/441) of the professionals in the studied area and $61.4 \%$ (137/223) of the distributed questionnaires. Of the professionals, $47.5 \%$ prescribe fluoride as a supplement during pregnancy. Sixty percent of professionals who prescribe fluoride believe that this procedure leads to a better dental formation and caries prevention in the baby. The professionals who do not prescribe prenatal fluoride graduated more recently than the professionals who prescribe it $(t=2.27, p<0.05)$. Moreover, the professionals who work exclusively in the public service prescribe less than those who work only in the private sector (Fisher exact test, $p<0.05$ ).

Conclusion: there is a large percentage of gynecologistobstetricians who still prescribe fluoride in the prenatal period, in spite of the recent studies that have not observed any benefit to the child. Therefore, there is a need to update these professionals about the mechanism of action, indication and clinical use of fluoride.

KEY WORDS: Fluoride, prenatal supplement. Buccal health. Prenatal care. Normal pregnancy.

\section{Referências}

1. Franco F. Fluoretos. In: Wannmacher L, Ferreira MBC. Farmacologia Clínica para Dentistas. $2^{a}$ ed. Rio de Janeiro: Guanabara-Koogan; 1999. p.30011 .

2. Limeback H. A re-examination of the pre-eruptive and post-eruptive mechanism of the anticarie effects of fluoride: is there any anticaries benefit from swallowing fluoride? Community Dent Oral Epidemiol 1999; 27:62-71. 
3. Silvertone LM, Johnson NW, Hardie JM, Williams

RAD. Dental caries, aetiology, pathology and 